\title{
MIST ve BRICS ülkelerinde Uluslararası Ticaret, Küreselleşme ve Fosil Enerji Kullanımı Çevresel Bozulmayı Nasıl Etkiliyor?: Panel Veri Analizi Tahmini
}

\author{
How Do International Trade, Globalization and Fossil Energy Use Affect \\ Environmental Degradation in MIST and BRICS countries?: Panel Data Analysis \\ Estimation
}

Asll ÖZPOLAT *

Metin YILDIRIM **

Ferda NAKIPOĞLU ÖZSOY ***

\begin{abstract}
$\ddot{O} Z$
Karbon emisyonundaki artış, çevre kirliliğinin en önemli sebeplerden biridir. Karbon emisyon oranlarl, iklim değişikliği gibi çevresel faktörler üzerinde belirgin derecede etkiye sahiptir. Ülkelerde karbon emisyonunun azaltılması ve küresel ısınmanın önlenmesi amacıyla çevre teknolojilerinin payının arttırllması önemli bir gerçektir. Gösterdikleri ekonomik performans, yüksek büyüme hızı, sanayileşme politikaları ve çabaları ile BRICS ve MIST ülkelerindeki karbon emisyonu da yüksektir. Çalışma kapsamında MIST ile BRICS ülkeleri için CO2 emisyonu ve emisyonu belirleyen faktörler arasındaki ilişki, 1990-2018 yılları arasında ikinci nesil panel veri analizi tahmin yöntemleri ile araştırılmıştır. Elde edilen sonuçları göre; her iki ülke grubunda Çevresel Kuznets Eğrisi hipotezi geçerlidir. MIST ülkelerinde kişi başına düşen milli gelir emisyonu \% 1.9 oranında artırırken, BRICS ülkelerinde bu artış \%1.1'dir. Küreselleşmenin etkisi; BRICS ülkelerinde pozitif ve anlamlı iken, MIST ülkelerinde negatif ve anlamlı olarak elde edilmiştir. Enerji kullanımı her iki ülke grubunun da karbon emisyonunu artırmaktadır. MIST ülkelerinde dışa açıklık anlamsız, BRICS ülkelerinde ise dışa açıklık karbon emisyonunu azaltmaktadır.
\end{abstract}

\section{ANAHTAR KELIMELER}

CO2 Emisyonu, Çevresel Bozulma, Panel Veri Analizi, MIST, BRICS

\begin{abstract}
The increase in carbon emissions is the most important cause of environmental pollution The carbon emission rates has a specific effect on many environmental factors, especially climate change. It is an important fact to increase the share of environmental technologies in order to reduce carbon emissions and prevent global warming in countries. With their economic performance, high growth rate, industrialization policies and efforts, carbon emissions in BRICS and MIST countries are also high. Within the scope of the study, the relationship between CO2 emission and emission determining factors for MIST and BRICS countries, second generation panel data analysis estimation methods has been researched between 1990-2018. According to the results obtained; In both country groups, the Environmental Kuznets Curve hypothesis is valid. While GDP per capita increases by $1.9 \%$ in MIST countries, this increase is $1.1 \%$ in BRICS countries. The effect of globalization; While it was positive and significant in BRICS countries, it was negative and significant in MIST countries. Energy use increases the carbon emissions of both country groups. In MIST countries, openness is meaningless, whereas in BRICS countries, openness reduces carbon emissions.
\end{abstract}

\section{KEYWORDS}

CO2 Emissions, Environmental Degradations, Panel Data Analysis, MIST, BRICS

\begin{tabular}{|c|c|c|}
\hline \multicolumn{2}{|r|}{$\begin{array}{c}\text { Makale Geliş Tarihi / Submission Date } \\
\text { 14.07.2021 }\end{array}$} & $\begin{array}{c}\text { Makale Kabul Tarihi / Date of Acceptance } \\
25.10 .2021\end{array}$ \\
\hline Atıf & $\begin{array}{l}\text { Özpolat, A., Yıldırım, M. ve Nakıp } \\
\text { Küreselleşme ve Fosil Enerji Kullanı1 } \\
\text { Üniversitesi Sosyal Bilimler Meslek Yi }\end{array}$ & $\begin{array}{l}\text { MIST ve BRICS ülkelerinde Uluslararası Ticaret, } \\
\text { Nası1 Etkiliyor?: Panel Veri Analizi Tahmini. Selçuk } \\
\text { 2), 475-484. }\end{array}$ \\
\hline
\end{tabular}

\footnotetext{
*Dr. Öğr. Üyesi, Gaziantep Üniversitesi Oğuzeli Meslek Yüksekokulu, asliozpolat@ gmail.com, ORCID: 0000-0002-1769-3654

** Dr. Öğr. Üyesi, Necmettin Erbakan Üniversitesi Uygulamalı Bilimler Fakültesi, myildirim@erbakan.edu.tr, ORCID: 0000-0002-7197-2523

*** Dr. Öğr. Üyesi, Gaziantep Üniversitesi İktisadi ve İdari Bilimler Fakültesi, nakipoglu@ gantep.edu.tr, ORCID: 0000-0002-5593-413X
} 


\section{GİRIŞ}

Ekonomik büyüme, uluslararası ticaret, sanayileşme, kentleşme, enerji kullanımı gibi ekonomik unsurlar gelişmiş ve gelişmekte olan ülkelerin birincil hedefleri arasında yer almaktadır. Bu hedeflerin elde edilmesi için mikro ve makro ölçekte birçok politika uygulamaktadır. Başarılı bir şekilde sürdürülen ekonomi politikalarının ülke ekonomilerine olumlu etki yaptığı, büyüme rakamlarını yükselttiği ve başka birçok göstergenin de iyileştiği görülmektedir. Buna karşın uygulanan ekonomi politikaları ülkelerin çevresel kalitesini üzerinde olumsuz sonuçlar ortaya koyabilmektedir. Özellikle yüksek ekonomik büyüme oranları enerji kullanımını artırarak çevresel sorunların büyümesine katkıda bulunmaktadır. Bunun yanında küreselleşme ve iklim değişikliği sonucunda eko-sistem üzerinde meydana gelen bozulmalar sosyo-ekonomik yap1 üzerinde de ciddi etkiler ortaya koymuştur. Literatürde bu etkiler üzerinde yapılan en önemli çalışmalardan biri Çevresel Kuznets eğrisidir. Çevresel Kuznets eğrisi büyüme ve gelir dağılımı ilişkisi üzerinde olan Kuznets eğrisinin (Kuznets, 1995) çevreye uyarlanmış halidir. Çevresel Kuznets Eğrisi yaklaşımına göre, çevresel kirlilik düzeyi ile ekonomik kalkınma sürecinde ters U şeklinde önce artış gözlemlenmekte ve belirli bir dönem sonrası düşüş meydana gelmektedir. Çevresel Kuznets eğrisinin geçerliliği ile ilgili yapılan çalışmalar incelendiğinde eğrinin geçerliliği ülkelere ve çalışılan zaman aralığına göre değişmektedir. Dolaysıyla bu alanda tek bir sonuçtan bahsetmek mümkün görünmemektedir. Çevresel Kuznets eğrisi ile ilgili yapılan çalışmalarda uluslararası ticaret, enerji kullanımı, fosil yakıt kullanımı, sanayileşme, küreselleşme vb. faktörlerin etkileri de araştırılmaktadır. Karbon emisyonu değerine bir çok faktör etki etmekte ve özellikle karbon emisyonunun uluslararası ticaret üzerinde önemli bir etkisi bulunmaktadır. Gelişmiş ülkeler ekonomik büyüklüklerini korumak ve piyasa avantajını eline geçirmek için, gelişmekte olan ülkelere yatırım yapmakta emisyon salınımı artmaktadır. Hızlı büyüme yaşayan, hızla sanayileşme çabasına giren ve sanayileşen ülkelerde de karbon emisyonu artışı dikkat çekmektedir.

Geleceğin lider piyasa ekonomileri olarak bahsedilen MIST ülkeler grubu (Meksika, Endonezya, Güney Kore ve Türkiye); son dönemde yükselen ekonomileri, nüfusu, pazar büyüklüğü, küresel GSYH'den en az \%1'lik pay almaları ve G-20 üyesi olmaları açısından önem arz etmekte ve bu ülkelerin karbon emisyonu dikkat çekmektedir. Diğer taraftan Dünya nüfusunun \%40'ını ve küresel Gayri Safi Yurtiçi Hasıla'nın yaklaşık $\% 25$ 'ine sahip olan BRICS (Brezilya, Rusya, Hindistan, Çin ve Güney Afrika) grubu ülkelerinin son yıllarda göstermiş oldukları ekonomik performansları ve bunun yanında salgılanan emisyon oranları da önem derecesinde değerlendirilmektedir. 2010 yılında BRICS grubu ülkelerinin toplam GSYH'si , 11 trilyon 872 milyon dolar iken, \%60 oranında artış göstererek 2019 yılında 19 trilyon 40 milyon dolara ulaşmıştır. Bu rakamın 11 trilyon 537 milyon dolarını tek başına Çin ekonomisi karşılarken, 2 trilyon 964 milyon dolarını da Hindistan ekonomisine aittir (Demir,2020:109-114). Dünya ticaretinde önemli bir yeri olan bu iki önemli ülke grubunun büyüme ve sanayileşme ile birlikte karbon emisyonu da artmıştır. Dolayısıyla çalışmanın amacı karşılaştırmalı olarak MIST ve BRICS ülkelerinden karbon emisyonunu belirleyen faktörlerin analiz edilmesi ve emisyona uluslararası ticaretin etkisinin ölçülmesidir. Bu amaçla yatay kesit bağımlılı̆ıını dikkate alan panel eşbütünleşme analizleri tahmin edilmiştir.

Çalışmanın mevcut literatüre katkısı şu şekildedir: i) MIST ve BRICS ülkeleri için karşılaştırmalı sonuçların ortaya konması ii) oluşturulan modellerin yeni nesil panel veri analiz yöntemleri ile tahmin edilmiş olmasıdır. Buna göre çalışmanın ilk bölümünde mevcut literatür yer almaktadır. İkinci bölümde model ve analiz sonuçları açılanırken son bölümde sonuç ve tartışmalara yer verilmiştir.

\section{LITERATÜR}

Hızla artan insan faaliyetlerinin bir sonucu olarak ortaya çıkan çevre kalitesindeki bozulma ve kirlilik seviyesinde yaşanan bir artış çevre sorunlarını son yıllarda ilgi odağı haline getirmiştir. Çevre kirliliğini etkileyen unsurların incelendiği çalışmaların temelinde yer alan EKC hipotezi bu alanda ilk çalışmalar olan Grossman ve Krueger (1991) ve Shafik ve Bandyopadhyay (1992)'nın temel alınmasıyla literatürde oldukça önem teşkil eden bir konu haline gelmiştir. Çevre kirliliğinin en önemli göstergelerinden biri olan karbon emisyonu ile ekonomik büyüme arasındaki bu ilişki farklı ekonometrik yöntemlerin uygulanması, periyotlardaki değişikliklerin söz konusu olması ve yeni değişkenlerin de kullanılması ile zamanla literatürde sıklıkla üzerinde tartışılan konu olmuştur. Bu nedenle çalışmanın literatür kısmında öncelikle EKC hipotezine ve enerji tüketimi ile dışa açıklık endeksinin karbon emisyonu üzerindeki etkilerinin incelendiği çalışmalara yer verilmiş, ardından fosil yakıt tüketiminin, küreselleşme endeksinin ve ekonomik büyümenin karbon emisyonu üzerinde etkilerinin test edildiği literatür çalışmalarından bahsedilmiştir.

\section{EKC, enerji tüketimi ve dışa açıklık endeksi}

Ekonomik büyümenin erken dönemlerinde çevresel tahribatın arttığı ancak belirli bir gelir eşiğinden sonra ekonomik büyümenin çevre kirliliğini azalttığını ifade eden EKC hipotezinin geçerliliğini test eden çalışmalara 
bakıldığında uygulanan yöntemlerin ya da ülke gruplarının farklılık göstermesine göre değişiklik gösterdiği görülmektedir. Öztürk ve Acaravcı (2013), Cho vd. (2014), Lau vd., (2014), Destek ve Özsoy (2015), Zhang vd. (2017), Çetin vd. (2018), Pata (2019), Uzar ve Eyuboğlu (2020) EKC hipotezinin geçerli olduğunu ileri süren çalışmalar iken Jebli ve Ben Youssef (2015), Farhani ve Öztürk (2015), Doğan ve Turkekul (2016), Koç ve Buluş (2020) aksi görüş bildiren çalışmalardır. Diğer yandan dışa açıklık oranı ve karbon emisyonu arasında da görüş birliğinin sağlanamadığı görülmektedir. Nitekim Shahbaz vd. (2017), Chen ve Lei (2018), Tachie vd. (2020) dışa açıklık endeksinin karbon emisyonunu artırdığını ifade ederken, Al-Mulali ve Öztürk (2016), Sinha vd. (2017) ile Amin vd. (2020) dışa açıklık endeksinin çevre kirliliğini azalttığı sonucuna varmışlardır.

Tablo 1'de EKC hipotezinin geçerliliğini sınayan ve enerji tüketimi ile dışa açıklık endeksinin karbon emisyonu üzerindeki etkilerinin araştırıldığ 1 çalışmaların özetine yer verilmiştir.

Tablo 1: Literatür Özeti

\begin{tabular}{|c|c|c|c|c|}
\hline Çalışma & Ülke ve Dönem & Değişkenler & Yöntem & Bulgular \\
\hline $\begin{array}{lll}\text { Tamazian } & \text { ve } & \text { Rao } \\
(2010) & & \end{array}$ & $\begin{array}{ll}24 & \text { geçiş } \\
\text { ekonomisi } & \\
1993-2004 & \\
\end{array}$ & $\begin{array}{l}\text { GDP, } \\
\text { CO2 }\end{array}$ & $\begin{array}{l}\text { GMM } \\
\text { tahmincisi }\end{array}$ & $\begin{array}{l}\text { TR, çevresel tahribatı } \\
\text { artırmaktadır. } \\
\text { EKC hipotezi geçerlidir. }\end{array}$ \\
\hline Shahbaz vd., (2013) & $\begin{array}{l}\text { Endonezya } \\
\text { 1975Q1-2011Q4 }\end{array}$ & $\begin{array}{l}\text { GDP, EC, TR, } \\
\mathrm{CO} 2\end{array}$ & $\begin{array}{l}\text { ARDL sinir testi } \\
\text { VECM Granger } \\
\text { nedensellik }\end{array}$ & $\begin{array}{l}\text { GDP ve EC karbon emisyonunu } \\
\text { artırmaktadır. TR ile } \mathrm{CO} 2 \text { arasında } \\
\text { geri besleme hipotezi geçerlidir. }\end{array}$ \\
\hline $\begin{array}{l}\text { Jebli ve Ben Youssef } \\
\text { (2015) }\end{array}$ & $\begin{array}{l}\text { Tunus } \\
1980-2009\end{array}$ & $\begin{array}{l}\text { GDP, REC, } \\
\text { TR, CO2 }\end{array}$ & $\begin{array}{l}\text { ARDL sinır testi } \\
\text { VECM Granger } \\
\text { nedensellik }\end{array}$ & $\begin{array}{l}\text { Kısa dönemde TR, GDP ve } \\
\text { CO2'den REC'ye doğru tek yönlü } \\
\text { nedensellik söz konusu iken uzun } \\
\text { dönemde TR'nin } \mathrm{CO} 2 \text { üzerinde } \\
\text { pozitif yönlü bir etkisi vardır. EKC } \\
\text { hipotezi geçerli değildir. }\end{array}$ \\
\hline $\begin{array}{l}\text { Farhani ve } \text { Öztürk } \\
(2015)\end{array}$ & $\begin{array}{l}\text { Tunus } \\
1971-2012\end{array}$ & $\begin{array}{l}\text { GDP, EC, TR, } \\
\mathrm{CO} 2\end{array}$ & $\begin{array}{l}\text { ARDL sinır testi } \\
\text { ECM } \\
\text { Granger } \\
\text { nedensellik }\end{array}$ & $\begin{array}{l}\text { GDP'den, GDP''den, kişi başına } \\
\text { EC'den kişi başına CO2'ye; kişi } \\
\text { başına CO2'den, GDP ve } \\
\text { GDP }^{2} \text { den ise TR doğru tek yönlü } \\
\text { nedensellik ilişkisi söz konusudur. } \\
\text { EKC hipotezi geçerli değildir. }\end{array}$ \\
\hline Omri vd., (2015) & $\begin{array}{l}12 \text { MENA ülkesi } \\
\text { 1990-2011 }\end{array}$ & $\begin{array}{l}\text { GDP, } \\
\text { CO2 }\end{array}$ & GMM & $\begin{array}{l}\text { CO2 ile GDP; GDP ile TR } \\
\text { arasinda çift yönlü nedensellik söz } \\
\text { konusudur. Ayrıa TR'dan } \\
\text { CO2'ye doğru tek yönlü } \\
\text { nedensellik söz konusudur. EKC } \\
\text { hipotezi geçerlidir. }\end{array}$ \\
\hline $\begin{array}{lll}\text { Doğan } & \text { ve } & \text { Şeker } \\
(2016) & & \end{array}$ & $\begin{array}{l}\text { En yüksek } \\
\text { yenilenebilir } \\
\text { enerji oranına } \\
\text { sahip ülkeler } \\
\text { 1985-2011 }\end{array}$ & $\begin{array}{lr}\text { GDP, } & \text { REC, } \\
\text { NREC, } & \text { TR, } \\
\text { CO2 } & \end{array}$ & DOLS, FMOLS & $\begin{array}{l}\text { REC ve TR'de meydana gelen bir } \\
\text { artış çevresel kaliteyi artırırken, } \\
\text { NREC'de ortaya çıan artış } \\
\text { çevresel tahribata neden } \\
\text { olmaktadır. } \\
\text { geçerlidir. }\end{array}$ \\
\hline Ertuğrul vd., (2016) & $\begin{array}{l}\text { Gelişmekte olan } \\
\text { ülkeler arasında } \\
\text { ilk on CO2 } \\
\text { salınımı } \\
\text { gerçekleştiren } \\
\text { ülkeler } \\
\text { 1971-2011 } \\
\end{array}$ & $\begin{array}{l}\text { GDP, TR, EC, } \\
\text { CO2 }\end{array}$ & $\begin{array}{lr}\text { ARDL } r & \text { Sinır } \\
\text { testi, VECM } \\
\text { Granger } \\
\text { nedensellik }\end{array}$ & $\begin{array}{l}\text { GDP, EC ve TR, uzun dönemde } \\
\text { CO2'nin temel belirleyicisidir. } \\
\text { EC'deki bir artış çevresel tahribata } \\
\text { yol açmaktadır. EKC hipotezi } \\
\text { Türkiye, Hindistan, Çin ve Kore } \\
\text { için geçerlidir. }\end{array}$ \\
\hline $\begin{array}{l}\text { Doğan ve Turkekul } \\
\text { (2016) }\end{array}$ & $\begin{array}{l}\text { ABD } \\
1960-2010\end{array}$ & GDP, EC, TR & $\begin{array}{l}\text { ARDL sinır testi } \\
\text { Granger } \\
\text { nedensellik }\end{array}$ & $\begin{array}{l}\text { TR, CO2'yi azaltıcı etkiye sahip } \\
\text { iken EC çevre kalitesini olumsuz } \\
\text { etkilemektedir. EKC hipotezi } \\
\text { geçerli değildir. }\end{array}$ \\
\hline $\begin{array}{l}\text { Hasson ve Masih } \\
\text { (2017) }\end{array}$ & $\begin{array}{l}\text { Güney Afrika } \\
\text { 1971-2013 }\end{array}$ & $\begin{array}{l}\text { GDP, EC, TR, } \\
\text { CO2 }\end{array}$ & $\begin{array}{l}\text { ARDL sinir } \\
\text { testi, ECM }\end{array}$ & $\begin{array}{l}\text { TR, CO2'nin neden } \\
\text { kirliliği azaldmağu } \\
\text { hipotezi geçerlidir. }\end{array}$ \\
\hline
\end{tabular}




\begin{tabular}{|c|c|c|c|c|}
\hline $\begin{array}{l}\text { Raza ve Shah } \\
\text { (2018) }\end{array}$ & $\begin{array}{l}\text { G7 } \\
1991-2016\end{array}$ & $\begin{array}{l}\text { GDP, REC, } \\
\text { TR, CO2 }\end{array}$ & $\begin{array}{l}\text { FMOLS } \\
\text { DOLS }\end{array}$ & \begin{tabular}{l}
\multicolumn{3}{l}{ Uzun dönemde GDP ve TR çevre } \\
kirliliğini artırmaktadır. REC, \\
CO2'yi azaltmaktadır. \\
hipotezi geçerlidir.
\end{tabular} \\
\hline Muhammad (2019) & $\begin{array}{lr}\begin{array}{l}\text { Gelişmiş, } \\
\text { gelişmekte }\end{array} \\
\text { Ortadoğu } & \text { olan, } \\
\text { Kuzey } & \text { Afrika } \\
\text { ülkeleri olmak } \\
\text { üzere toplam } 68 \\
\text { ülke } & \\
2001-2017 & \end{array}$ & $\begin{array}{l}\text { GDP, EC, TR, } \\
\text { CO2 }\end{array}$ & $\begin{array}{l}\text { SUR, GMM, } \\
\text { Sys GMM }\end{array}$ & $\begin{array}{l}\text { EC'deki artış nedeniyle tüm } \\
\text { ülkelerde CO2 artmaktadır. } \\
\text { CO2'deki artış nedeniyle MENA } \\
\text { dişındaki tüm ülkelerde GDP } \\
\text { artmaktadır. MENA ve gelişmiş } \\
\text { ülkelerde EC azalırken, CO2 } \\
\text { artmaktadır. GDP'deki artıştan } \\
\text { kaynaklı olarak gelişmekte olan } \\
\text { ülkelerde CO2 azalmakta, EC } \\
\text { artmaktadır. TR, SUR ve GMM } \\
\text { modellerinde pozitif bir ilişkiye } \\
\text { ifade ederken, Sys GMM } \\
\text { sonuçlarına göre enerji tüketimi } \\
\text { üzerinden negatif ve istatistiki } \\
\text { olarak anlamsız bir etkiye sahiptir. }\end{array}$ \\
\hline $\begin{array}{l}\text { Koç ve Buluş } \\
(2020)\end{array}$ & $\begin{array}{l}\text { Güney Kore } \\
1971-2017\end{array}$ & $\begin{array}{l}\text { GDP, } \quad \text { EC, } \\
\text { REC, TR, CO2 }\end{array}$ & ARDL sinir testi & $\begin{array}{l}\text { GDP ve EC'deki artış çevresel } \\
\text { tahribata yol açarken, REC ve } \\
\text { TR çevre kirliliğinin azalmasına } \\
\text { neden olmaktadır. EKC hipotezi } \\
\text { geçerli değildir. }\end{array}$ \\
\hline $\begin{array}{l}\text { Özpolat ve Özsoy } \\
\text { (2021) }\end{array}$ & $\begin{array}{l}\text { Türkiye } \\
1990-2015\end{array}$ & $\begin{array}{l}\text { GDP, } \\
\text { NREC, } \\
\text { CO2 }\end{array}$ & ARDL sinir testi & $\begin{array}{l}\text { REC, CO2'yi azaltırken; NREC, } \\
\text { CO2'yi arttırmaktadır. TR kisa } \\
\text { dönemde çevre kalitesini olumlu } \\
\text { etkilerken, uzun dönemde } \\
\text { istatistiki olarak anlamsızdır. EKC } \\
\text { hipotezi geçerlidir. }\end{array}$ \\
\hline
\end{tabular}

Not: GDP (ekonomik büyüme///reel GSYİH), TR (dışa açıklık endeksi), EC (enerji tüketimi), REC (yenilenebilir enerji tüketimi), NREC (yenilenemeyen enerji tüketimi), $\mathrm{CO} 2$ (karbon emisyonu)

\section{Fosil yakıt tüketimi, küreselleşme ve karbon emisyonu}

Rafindadi vd., (2014) 1975-2012 döneminde seçili 10 Asya-Pasifik ülkeleri için fosil yakıt enerji tüketimi ile karbon emisyonu arasındaki ilişkiyi incelemiş; Çin, Japonya, Malezya, Singapur, Filipinler ve Brunie'de fosil yakıt enerji tüketiminin karbondioksit emisyonu ile önemli ve pozitif bir ilişkisi olduğu sonucuna ulaşmışlardır. Ayrıca Japonya'da fosil yakıt enerji tüketimi ile karbon emisyonu arasında birebir ilişki tespit edilmiştir. Lotfalipour vd., (2010). 1967-2007 gözlem aralığında İran için karbon emisyonu, ekonomik büyüme ve fosil yakıt tüketimi arasındaki ilişkiyi Toda-Yamamoto nedensellik testi ile araştırmıştır. Uzun dönemde GSYİH'dan enerji tüketiminin önemli temsilcilerinden olan petrol ürünleri ve doğal gaz tüketimine tek yönlü nedensellik tespit ederken, toplam fosil yakıt tüketiminden karbon emisyonuna doğru herhangi bir nedensellik söz konusu olmadığı sonucuna ulaşılmıştır. Bimanatya (2018) 1965-2012 yıllarını kapsayan dönemde Endenozya için Gayri Safi Yurt İçi Hasıla, fosil yakıt tüketimi (petrol, doğalgaz ve kömür) ve karbon emisyonu arasındaki kısa ve uzun dönemli nedensellik ilişkisini incelemiş, VECM Granger nedensellik testi sonunda elde edilen bulgular neticesinde kısa dönemde kömür tüketiminden Gayri Safi Yurt İçi Hasılaya, Gayri Safi Yurt İçi Hasıladan ise petrol tüketimine doğru tek yönlü nedensellik tespit edilmiştir. Uzun dönemde diğer tüm değişkenler çift yönlü nedenselliğe sahip iken sadece petrol tüketiminden Gayri Safi Yurt İçi Hasılaya ve karbon emisyonuna tek yönlü nedensellik olduğu sonucuna ulaşılmıştır.

Gökmenoğlu ve Sadeghieh (2019) karbon emisyonu, fosil yakıt tüketimi, finansal kalkınma ve ekonomik büyüme arasındaki ilişkiyi Türkiye için 1960-2011 dönem aralığında incelemiştir. Uzun dönemde ekonomik büyümenin karbon emisyonu üzerinde negatif ve istatistiki olarak anlamlı bir etkiye sahip iken, fosil yakıt tüketiminin karbon emisyonu üzerinde pozitif bir etki ortaya çıkardığı sonucuna ulaşılmıştır. Rafindadi ve Usman (2019) Güney Afrika'da küreselleşme, enerji kullanımı ve çevresel tahribat arasındaki ilişkiyi 10712014 dönemi için araştırmışlar ve EKC hipotezinin geçerli olduğu sonucunu elde etmişlerdir. Diğer yandan küreselleşmenin, ülkenin ulaştı̆̆ ekonomik büyüme derecesine bakılmaksızın kısa vadede çevresel bozulmayı yoğunlaştırdığı tespit edilmiştir. Enerji kullanımından çevresel bozulmaya doğru tek yönlü, ekonomik büyüme ile küreselleşme arasında ise çift yönlü nedensellik olduğu sonucuna ulaşılmıştır. Ayrıca enerji kullanımı ile küreselleşmenin çevresel bozulmaya yol açtığı ve kirletici emisyonlardaki artışın, çoğunlukla fosil yakıtlardan elde edilen enerji kullanımına bağlı olduğu sonucu da elde edilen bulgular arasında yer almaktadır. 
Khan vd., (2019) 1971-2016 döneminde Pakistan'da küreselleşmenin, ekonomik faktörlerin ve enerji tüketiminin karbon emisyonu üzerindeki etkilerini dinamik ARDL sınır testi yaklaşımı ile incelemiş, elde edilen bulgular neticesinde enerji tüketiminin, dışa açıklık endeksinin, ekonomik-sosyal ve politik küreselleşmenin karbon emisyonu üzerinde pozitif yönlü bir etkiye sahip olduğu sonucuna ulaşılmıştır. Destek (2019) 1995-2015 periyodunda Orta ve Doğu Avrupa ülkelerinde ekonomik, sosyal ve politik küreselleşmenin çevre kirliliği üzerindeki etkilerini incelemiş; ekonomik ve sosyal küreselleşmenin karbon emisyonunu artırırken, politik küreselleşmenin çevresel kirliliği azalttığı sonuna ulaşmıştır. Ayrıca elde edilen bulgular sonucunda EKC hipotezinin geçerli olduğu da tespit edilmiştir. Kalaycı ve Hayaloğlu (2019) yılında yaptıkları çalışmada NAFTA ülkeleri için 1990-2015 yıllarında ekonomik küreselleşme, dışa açıklık endeksi ve karbon emisyonu arasındaki ilişkiyi incelemişlerdir. Elde edilen bulgular ekonomik küreselleşme, dışa açıklık endeksi ve karbon emisyonu arasında pozitif yönlü bir ilişkinin varlı̆̆ını göstermektedir. Aynı zamanda çalışmada EKC hipotezinin geçerli olmadığı sonucuna da ulaşılmıştır. Liu vd., (2020) G7 ülkeleri için 1970-2015 dönemini kapsayan süreçte KOF küreselleşme endeksinin, yenilenebilir enerji tüketiminin ve ekonomik büyümenin karbon emisyonu üzerindeki etkilerini test etmişlerdir. Elde edilen ampirik bulgular neticesinde küreselleşme ile karbon emisyonu arasında ters- $U$ şeklinde bir ilişki elde edilirken, EKC hipotezinin geçerli olduğu sonucuna varılmıştır. Diğer yandan yenilenebilir enerji tüketiminin artması çevre kirliliğini azaltmaktadır.

\section{VERI VE METODOLOJI}

Çalışma kapsamında MIST ( Meksika, Endonezya, Güney Kore ve Türkiye) ile BRICS ( Brezilya, Rusya, Hindistan, Çin ve Güney Afrika) ülkeleri için $\mathrm{CO} 2$ emisyonu ve emisyonu belirleyen faktörler arasındaki ilişki araştırılmıştır. Panel modelde zaman aralı̆̆ 1990-2018 yılları için belirlenmiştir. Bunun temel nedeni Rusya'nın 1990 öncesi dönemde SSCB içinde yer alması ve bu dönem öncesinde ülkeye ait verilerin bulunmamasından kaynaklamaktadır. MIST ve BRICS ülkeleri yeni sanayileşen güçlü ekonomiler olarak ifade edilmektedirler. BRICS ülkeleri, üye ülkeler arasındaki sanayi ve ticaret ilişkisinin güçlendirilmesi amacıyla kurulmuştur. MIST ülkeleri ise hızlı büyüme rakamları ve sanayileşme çabaları dolayısıyla geleceğin önemli sanayileşen ülkeleri arasında yer almaktadır. Bu ülke gruplarının karşılaştırılmasının temel nedeni, sanayileşen ülkelerin karbon emisyonunun yüksek olması ve bu emisyonu belirleyen faktörlerin incelenmesinin gerekliliğidir. Dolayısıyla bu ülke grupları için karşılaştırmalı olarak karbon emisyonu ve emisyonu belirleyen faktörler analiz edilecektir. Şekil 1'de MIST ve BRICS ülkeleri için karbon emisyonu gösterilmektedir.

\section{Şekil 1: MIST ve BRICS Ülkeleri CO2 Emisyonu}
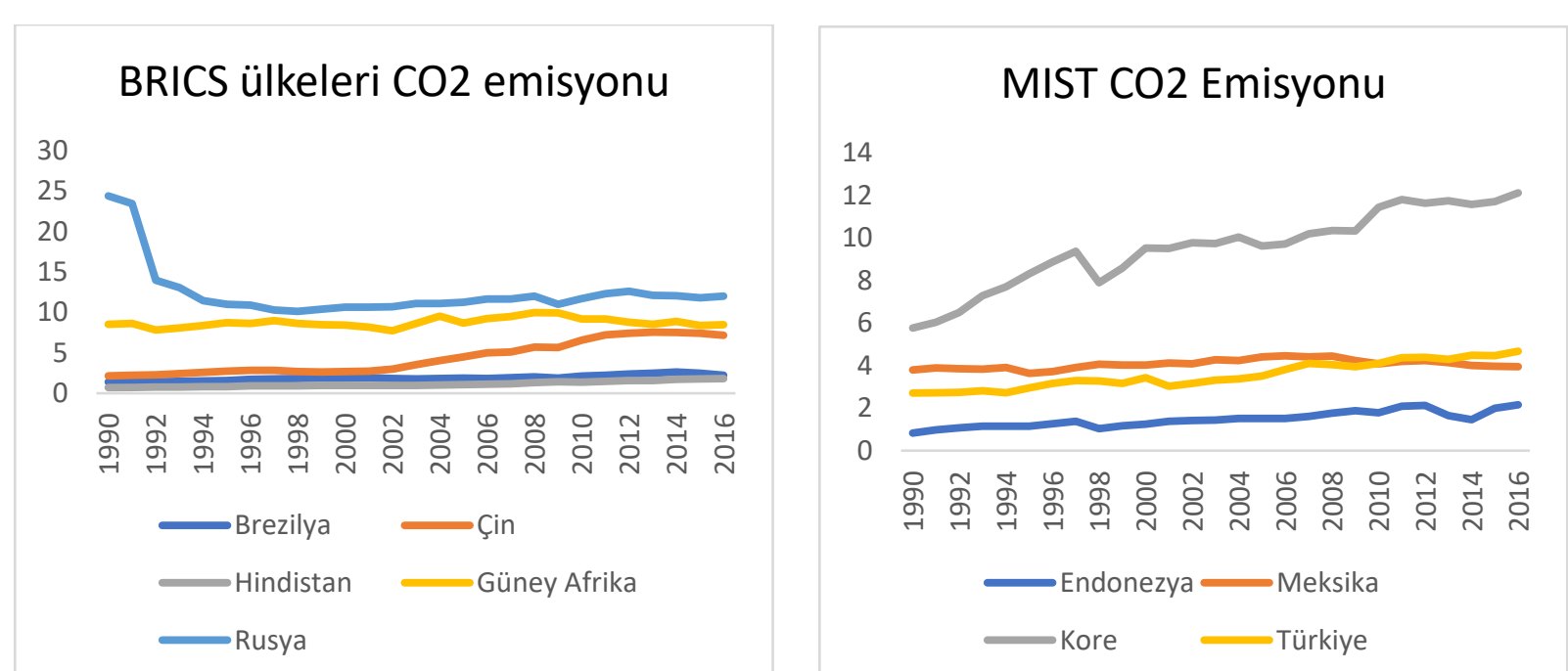

Şekilde yer alan veriler incelendiğinde MIST ülkelerin en yüksek emisyon değeri Kore'ye en düşük değer ise Endonezya'ya aittir. BRICS ülkelerinde ise Rusya CO2 emisyonu en yüksek olan ülkedir. Tüm ülkeler için emisyon değerinin giderek arttığı da görülmektedir. Bu artışın nedenleri, artışı belirleyen faktörler bir model yardımıyla incelenmiştir. Modelde bağımlı değişken olarak CO2 emisyonu (kişi başına metrik ton) kullanılmıştır. Bağımsız değişkenler ise küreselleşme indeksi, kişi başına düşen GSYH (reel, 2010 ABD\$), kişi başına düşen GSYİH'nın karesi, dışa açıklık (GSYH içindeki \% pay), ve enerji kullanımıdır (kişi başına). 
Küreselleşme endeksi, KOF İsveç ekonomi enstitüsünden, $\mathrm{CO} 2$ emisyonu ve enerji tüketimi Uluslararası enerji ajansından (IEA) ve diğer değişkenler dünya bankası veri tabanından elde edilmiştir.

$$
\operatorname{InCO} O_{i, t}=\alpha_{0}+\alpha_{1} \operatorname{In} Y_{i, t}+\alpha_{2} \operatorname{InY}_{i, t}^{2}+\alpha_{3} \operatorname{InGL}_{i, t}+\alpha_{4} \operatorname{InEU_{i,t}}+\alpha_{5} \operatorname{InTR}_{i, t}+\varepsilon_{i, t}
$$

Modelde $\mathrm{t}$, i ve $\varepsilon_{i, t}$ sirasiyla, zaman periyodu, yatay kesit ve hata terimini InCO $\boldsymbol{O}_{i, t}$ toplam CO2 emisyonunun doğal logaritmasını, In $Y_{i, t}$ kişi başına GSYİH'y1, In $Y^{2}{ }_{i, t}$ kişi başına GSYİH'nın karesinin, InTR $_{i, t}$ dışa açıklığ $1, \quad$ InGL $L_{i, t}$ globalleşme endeksini ve InENU $U_{i, t}$ enerji kullanımının doğal logaritmasını ifade etmektedir. Bu kapsamda EKC hipotezinin geçerli olabilmesi için $\left.\alpha_{1}\right\rangle 0$ ve $\alpha_{2}\langle 0$ sonuçlarının elde edilmesi gerekmektedir.

Çalışmada yatay kesit bağımlılığı öncelikli olarak test edilmiştir. Yatay kesit bağımlılığı paneli oluşturan birimlerin birinde meydana gelen bir değişimin ya da kırılmanın panelin diğer birimlerini etkilemeyeceğini ifade eder. Ancak küresel ölçekte ülkeler arasında yakın ilişkilerin ve ticaretin boyutu dikkate alındığında ülkelerin birbirinden etkilenmemesi olası görünmemektedir. Yatay kesit bağımlılığı CD test ile analiz edilmiştir. Breush Pagan (1980) ve Pesaran (2004) tarafından geliştirilen CD test şu şekildedir:

$$
C D=\sqrt{\frac{2 T}{N(N-1)}}\left(\sum_{i=1}^{N-1} \sum_{j=i+1}^{N} \hat{\rho}_{i j}\right)
$$

Elde edilen sonuçlar Tablo 2'de yer almaktadır.

Tablo 2: CD Test Sonuçları

\begin{tabular}{lllllll}
\hline \hline & & & & & \\
& & INCO & INY & INGL & INEU & INTR \\
\hline \multirow{3}{*}{ MIST } & Pesaran CD test & 0.61 & 12.26 & 12.62 & 9.86 & 2.82 \\
& P-Value & 0.539 & 0.000 & 0.000 & 0.000 & 0.005 \\
BRICS & Pesaran CD test & 6.96 & 15.35 & 16.73 & 10.04 & 8.11 \\
\hline \hline
\end{tabular}

Elde edilen sonuçlara göre MIST ülkelerinde karbon emisyonu dışındaki tüm değişkenlerde Yatay Kesit Bağımlılığı vardır boş hipotezi reddedilmektedir. Yani değişkenler karbon emisyonu dışındaki değişkenler arasında Yatay Kesit Bağımlılığı bulunmaktadır. Yatay kesit bağımlılığı nedeniyle bu aşamadan sonra test edilen tüm yöntemler bağımlılı̆̆ı dikkate alan testlerdir. Ayrıca bu testler bağımlılık yokken de kullanılabilir. Dolayısıyla karbon emisyonu değişkeninde yatay kesit bağımlılığı bulunmaması analiz yöntemini değiştirmemektedir. Değişkenlerin birim kök testleri Yatay Kesit Bağımlılı̆̆ını dikkate alan CIPS testi Pesaran (2007) ile analiz edilmiştir. Sonuçlar Tablo 3' de yer almaktadır.

\begin{tabular}{|c|c|c|c|c|c|}
\hline \multirow[t]{3}{*}{ Ülke Grubu } & \multirow[t]{3}{*}{ Değişkenler } & \multicolumn{4}{|c|}{ CIPS } \\
\hline & & \multicolumn{2}{|c|}{ Düzey } & \multicolumn{2}{|c|}{ Fark } \\
\hline & & Sabit & Sabit \&Trend & Sabit & Sabit \&Trend \\
\hline \multirow{3}{*}{ MIST } & INCO & -1.148 & -3.128 & -5.573 & -5.683 \\
\hline & INY & -1.765 & -1.918 & -4.748 & -5.220 \\
\hline & INGL & -2.491 & -3.364 & -5.284 & -5.255 \\
\hline \multirow{7}{*}{ BRICS } & INEU & -2.686 & -2.483 & -5.247 & -5.489 \\
\hline & INTR & -1.446 & -2.315 & -4.077 & -3.986 \\
\hline & INCO & -2.170 & -1.206 & -3.260 & -3.546 \\
\hline & INY & -1.846 & -1.458 & -2.890 & -3.414 \\
\hline & INGL & -2.473 & -2.274 & -5.219 & -5.759 \\
\hline & INEU & -2.413 & -1.978 & -3.814 & -3.965 \\
\hline & INTR & -2.745 & -2.817 & -5.045 & -5.048 \\
\hline
\end{tabular}

Tablo 3. CIPS Birim Kök Testi Sonuçları

Not: Sabit için kritik değerler: *10\%; -2.12; **\%5; -2.25, ***\%1; -2.51 Sabit ve Trend için kritik değerler: *10\%; -2.76; **\%5; -2.94, ***\%1; -3.33 
Birim kök sonuçlarının değerlendirmesi yapılırken olasılık değerleri \%1 olarak kabul edilmiştir. \%5 ve $\% 10$ olasılık düzeylerinde de durağan olarak elde edilen değişkenler, kabul edilen olasılık değerinde durağan olmadıklarından fark durağanlardır. Bu olasılık düzeyinde sonuçlara göre tüm değişkenler birinci derecede fark durağandır. Yani tüm değişkenler I(1) düzeyde eşbütümleşiktir. Değişkenlerin birinci dereceden durağan olması eşbütünleşme analizinin yapılmasına olanak tanımaktadır. Çalışmada eşbütünleşmenin varlığı Westerlund ECM eşbütünleşme analizi (2007) ile araştırılmıştır. Westerlund (2007) Eşbütünleşme analizi kapsamında eşbütünleşme yoktur boş hipotezi ve alternatif hipotez ortalama grup ve panel testi olarak iki farklı test olarak oluşturulmuştur. Bu aşamada hata düzeltme modeline göre dört tane eşbütünleşme test istatistiği $\left(G_{\alpha}, G_{t}, P_{\alpha}, P_{t}\right)$ oluşturmuştur. Analize göre değişkenlerin I(1)'de durağan olmaları gerekmektedir. Sonuçlar Tablo 4' de yer almaktadir.

Tablo 4. Panel Eşbütünleşme Testi Sonuçları

\begin{tabular}{lll}
\hline \hline Test & MIST & BRICS \\
\hline \hline Westerlund_ECM & Value & Value \\
$\mathrm{G}_{\mathrm{T}}$ & & \\
$\mathrm{G}_{\alpha}$ & $-1.517(0.065)$ & $-7.564(0.000)$ \\
$\mathrm{P}_{\mathrm{T}}$ & $-1.774(0.038)$ & $0.464(0.679)$ \\
$\mathrm{P}_{\alpha}$ & $0.476(0.683)$ & $-4.454(0.000)$ \\
\hline \hline
\end{tabular}

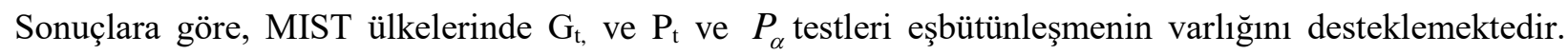
Dolayısıyla MIST ülkelerinde değişkenler arasında eşbütünleşmenin varlığı elde edilmiştir. BRICS ülkelerinde ise $\mathrm{G}_{\mathrm{t}}$, ve $\mathrm{P}_{\mathrm{t}}$ sonuçları eşbütünleşmenin varlığını desteklemekte ancak $\mathrm{G}_{\alpha}$ ve $P_{\alpha}$ testleri ise eşbütünleşmenin varlığını reddetmektedir. Buna göre $G_{t}$, ve $P_{t}$ testleri dikkate alındığında değişkenler arasında eşbütünleşme bulunmaktadır. Eşbütünleşmenin varlığının tespitinden sonra parametre tahmini aşamasına geçilmiştir. Parametre tahminleri FMOLS Pedroni (2000) tahmincisi ile incelenmiştir. FMOLS Panel tahmincisi $\hat{\beta}_{G F M}=N^{-1} \sum_{i=1}^{N} \beta_{F M i}^{*}$ şeklinde formüle edilmiştir.

Tablo 5. Eşbütünleşme Tahmincisi Sonuçları

\begin{tabular}{|c|c|c|}
\hline & MIST & BRICS \\
\hline Değișenler & FMOLS & FMOLS \\
\hline INY & $1.990 * *$ & $1.013 * * *$ \\
\hline INY2 & $-0.129 * *$ & $-0.090 * * *$ \\
\hline INGL & $-1.500 *$ & $0.165 * *$ \\
\hline INEU & $0.723 * *$ & $1.228 * *$ \\
\hline INTR & -0.228 & $-0.080 * *$ \\
\hline
\end{tabular}

Olasılık değerleri; *,10\%; **,\%5; ***,\%1

Genel olarak literatür incelendiğinde karbon emisyonunu etkileyen bir çok faktör bulunmaktadır. $\mathrm{Bu}$ faktörlerin emisyona etkisi ülke grubuna ve zaman aralığına göre değişebilmektedir. Bu çalışmada tahmin edilen FMOLS sonuçlarına göre her iki ülke grubunda çevresel Kuznets eğrisi geçerlidir. MIST ülkelerinde kişi başına düşen milli gelir emisyonu \% 1.9 oranında artıırken, BRICS ülkelerinde bu artış \%1.1'dir. Küreselleşmenin etkisi BRICS ülkelerinde pozitif ve anlamlı olarak, MIST ülkelerinde ise negatif ve anlamlı olarak elde edilmiştir. Enerji kullanımı her iki grubunda karbon emisyonunu artırmaktadır. Dışa açıklık ise MIST ülkelerinde anlamsızdır. BRICS ülkelerinde ise dışa açıklık karbon emisyonunu azaltmaktadır Sonuçlar, Doğan ve Turkekul (2016), Al-Mulali ve Öztürk (2016), Hasson ve Masif (2017), Sinha vd. (2017), Gökmenoğlu ve Sadeghieh (2019) ve Amin vd. (2020) çalışmalarıyla uyumludur.

\section{SONUÇ VE TARTIŞMA}

Küreselleşme, hızlı büyüme ve sanayileşme ile birlikte çevre de olumsuz etkilenmiştir. Gelişmiş ve gelişmekte olan ülkelerin, büyüme ve kalkınma uğruna çevre kirliliğine sebep oldukları, çevresel bozulma ve kirliliklerin önce hızla arttı̆̆ ama sonradan azaldığı yapılan çalışmalarla tespit edilmiştir. 
MIST ve BRICS ülkeleri yapılan projeksiyonlara göre önümüzdeki 20-30 y1lın küresel güçleri olarak değerlendirilmektedir. Çalışma kapsamında MIST (Meksika, Endonezya, Güney Kore ve Türkiye) ile BRICS ( Brezilya, Rusya, Hindistan, Çin ve Güney Afrika) ülkeleri için $\mathrm{CO} 2$ emisyonu ve emisyonu belirleyen faktörler arasındaki ilişki araştırılmıştır. Panel modelde zaman aralığı 1990-2018 yılları için belirlenmiştir. MIST ülkelerin en yüksek emisyon değeri Kore'ye en düşük değer ise Endonezya'ya aittir. BRICS ülkelerinde ise Rusya $\mathrm{CO} 2$ emisyonu en yüksek olan ülkedir. Tüm ülkeler için emisyon değerinin giderek arttığı da görülmektedir. Bu artışın nedenleri, artışı belirleyen faktörler bir model yardımıyla incelenmiştir.

Karbon emisyonunu etkileyen faktörlerin emisyona etkisi ülke grubuna ve zaman aralı̆̆na göre değişebilmektedir. Bu çalışmada tahmin edilen FMOLS sonuçlarına göre her iki ülke grubunda Çevresel Kuznets Eğrisi geçerlidir. MIST ülkelerinde kişi başına düşen milli gelir emisyonu \% 1.9 oranında artırırken, BRICS ülkelerinde bu artış \%1.1'dir. Küreselleşmenin etkisi BRICS ülkelerinde pozitif ve anlamlı olarak, MIST ülkelerinde ise negatif ve anlamlı olarak elde edilmiştir. Enerji kullanımı her iki grubun da karbon emisyonunu artırmaktadır. Dışa açıklık ise MIST ülkelerinde anlamsızdır. MIST ülkelerinde dışa açıklı̆̆ın $\mathrm{CO} 2$ emisyonu üzerinde anlamsız olması, yoğun kirlilik yaratan endüstrilere yönelimin henüz düşük seviyede olması şeklinde açıklanabilir. BRICS ülkelerinde ise dışa açıklık karbon emisyonunu azaltmaktadır.

Hem incelediğimiz ülke grupları hem de diğer ülkeler için Sürdürebilir Kalkınmanın önemi bir kez daha ortaya konmaktadır. Küreselleşmenin, büyümenin, enerji kullanımının ve dışa açıklık oranının karbon emisyonunu etkilediği bir gerçektir. Çevre kirliliği ve küresel iklim değişikliğinin olumsuz etkilerini ortadan kaldırmak için, ülkelerin ortak hareket etmeleri, uygun büyüme ve kalkınma politikaları uygulamaları, çevre teknolojileri payı artışı kaçınılmazdır. 


\section{KAYNAKLAR}

Al-Mulali, U., \& Öztürk, İ. (2016). The investigation of environmental Kuznets curve hypothesis in the advanced economies: The role of energy prices. Renew Sust Energ Rev, 54, 1622-1631.

Amin, A., Aziz, B., \& Liu, X. H. (2020). The relationship between urbanization, technology innovation, trade openness, and $\mathrm{CO} 2$ emissions: Evidence from a panel of Asian countries. Environmental Science and Pollution Research, 115.

Bimanatya, T. E. (2018). Fossil fuels consumption, carbon emissions, and economic growth in Indonesia.

Breusch, T. S., ve Pagan, A. R. (1980), The Lagrange Multiplier Test and Its Applications to Model Specification in Econometrics. The Review of Economic Studies, 47(1), ss:239-253.

Chen, W., \& Lei, Y. (2018). The impacts of renewable energy and technological innovation on environment-energygrowth nexus: New evidence from a panel quantile regression. Renew Energy, 123, 1-14.

Cho, C. H., Chu, Y. P. \& Yang, H. Y. (2014). An environment kuznets curve for ghg emissions: a panel cointegration analysis. Energy Sources, Part B: Economics, Planning, and Policy, 9(2), 120-129.

Çetin, M., Ecevit, E., \& Yucel, A. G. (2018). The impact of economic growth, energy consumption, trade openness, and financial development on carbon emissions: empirical evidence from Turkey. Environmental Science and Pollution Research, 25(36), 36589-36603

Demir, M. A. (2020) BRICS Ülkelerinde Ticari Dinamikler: Türkiye ile BRICS Grubu Ülkelerin Ticari Yoğunluk Analizi Bilecik Şeyh Edebali Üniversitesi Sosyal Bilimler Dergisi, TBMM 100. Yıl Özel Sayıs1, 109-133 DOI: 10.33905/bseusbed.748704

Destek, M. A. (2020). Investigation on the role of economic, social, and political globalization on environment: evidence from CEECs. Environmental Science and Pollution Research, 27(27), 33601-33614.

Destek, M. A. \& Ozsoy, F. N. (2015). Relationships between economic growth, energy consumption, globalization, urbanization and environmental degradation in Turkey International Journal of Energy and Statistics, 3(4), 1 - 13.

Doğan, E., \& Turkekul, B. (2016). CO2 emissions, real output, energy consumption, trade, urbanization and financial development: Testing the EKC hypothesis for the USA. Environmental Science and Pollution Research, 23(2), $1203-1213$

Dogan, E., \& Seker, F. (2016). The influence of real output, renewable and non-renewable energy, trade and financial development on carbon emissions in the top renewable energy countries. Renewable and Sustainable Energy Reviews, 60, 1074-1085.

Ertugrul, H. M., Cetin, M., Seker, F., \& Dogan, E. (2016). The impact of trade openness on global carbon dioxide emissions: Evidence from the top ten emitters among developing countries. Ecological Indicators, 67, 543-555.

Farhani, S., \& Ozturk, I. (2015). Causal relationship between CO 2 emissions, real GDP, energy consumption, financial development, trade openness, and urbanization in Tunisia. Environmental Science and Pollution Research, 22(20), $15663-15676$.

Gokmenoglu, K. K., \& Sadeghieh, M. (2019). Financial development, CO2 emissions, fossil fuel consumption and economic growth: the case of Turkey. Strategic Planning for Energy and the Environment, 38(4), 7-28.

Grossman, G. M., \& Krueger, A. B. (1991). Environmental impacts of a north American free trade agreement, NBER Working Paper, No.3914, Washington.

Hasson, A., \& Masih, M. (2017). Energy consumption, trade openness, economic growth, carbon dioxide emissions and electricity consumption: evidence from South Africa based on ARDL.

International Energy Agency (IEA) (2021). Data and Statistics. https://www.iea.org/data-and-statistics

Jebli, M. B., \& Youssef, S. B. (2015). The environmental Kuznets curve, economic growth, renewable and non-renewable energy, and trade in Tunisia. Renewable and Sustainable Energy Reviews, 47, 173-185.

Kalayc1, C. (2019). The impact of economic globalization on CO2 emissions. International Journal of Energy Economics and Policy, 2019, 9(1), 356-360.

Khan, M. K., Teng, J. Z., Khan, M. I., \& Khan, M. O. (2019). Impact of globalization, economic factors and energy consumption on CO2 emissions in Pakistan. Science of the total environment, 688, 424-436.

Koc, S., \& Bulus, G. C. (2020). Testing validity of the EKC hypothesis in South Korea: role of renewable energy and trade openness. Environmental Science and Pollution Research, 27(23), 29043-29054.

KOF Swiss Economic Institute (2021). KOF Time Series Database. https://www.iea.org/data-and-statistics

Kuznets, S., (1955). "Economic Growth and Income Equality", American Economic Review, 45, 1, 1- 28.

Lau, L. S., Choong, C. K., \& Eng, Y. K. (2014). Investigation of the environmental kuznets curve for carbon emissions in Malaysia: do foreign direct investment and trade matter?. Energy Policy, 68, 490-497.

Liu, M., Ren, X., Cheng, C., \& Wang, Z. (2020). The role of globalization in CO2 emissions: a semi-parametric panel data analysis for G7. Science of the Total Environment, 718, 137379.

Lotfalipour, M. R., Falahi, M. A., \& Ashena, M. (2010). Economic growth, CO2 emissions, and fossil fuels consumption in Iran. Energy, 35(12), 5115-5120.

Muhammad, B. (2019). Energy consumption, CO2 emissions and economic growth in developed, emerging and Middle East and North Africa countries. Energy, 179, 232-245. 
Omri, A., Daly, S., Rault, C., \& Chaibi, A. (2015). Financial development, environmental quality, trade and economic growth: What causes what in MENA countries. Energy Economics, 48, 242-252.

Özpolat, A., \& Özsoy, F. N. (2021). Yenilenebilir Enerji Kaynakları Çevresel Bozulmayı Azaltıyor Mu? Türkiye Örneği. Akademik Araştırmalar ve Çalışmalar Dergisi (AKAD), 13(24), 49-60.

Öztürk, I. \& Acaravc1, A. (2013). The long-run and causal analysis of energy, growth, openness and financial development on carbon emissions in Turkey. Energy Economics, 36, 262-267.

Pata, U. K. (2019). Environmental kuznets curve and trade openness in Turkey: bootstrap ardl approach with a structural break. Environmental Science and Pollution Research, 26(20), 20264-20276.

Pedroni, P. (2000). Fully Modified OLS for Heterogeneous Cointegrated Panels. Nonstationary Panels, Panel Cointegration and Dynamic Panels, Volume 15, ss:93-130.

Pesaran, M.H. (2004). General Diagnostic Tests for Cross Section Dependence in Panels. IZA Discussion Paper, 1240

Pesaran, M.H., (2007). A simple panel unit root test in the presence of cross-section dependence. J. Appl. Econ. 22 (2), ss: $265-312$

Rafindadi, A. A., \& Usman, O. (2019). Globalization, energy use, and environmental degradation in South Africa: startling empirical evidence from the Maki-cointegration test. Journal of environmental management, 244, 265275.

Rafindadi, A. A., Yusof, Z., Zaman, K., Kyophilavong, P., \& Akhmat, G. (2014). The relationship between air pollution, fossil fuel energy consumption, and water resources in the panel of selected Asia-Pacific countries. Environmental Science and Pollution Research, 21(19), 11395-11400.

Raza, S. A., \& Shah, N. (2018). Testing Environmental Kuznets Curve hypothesis in G7 countries: The role of renewable energy consumption and trade. Environmental Science and Pollution Research, 25(27), 26965-26977.

Shafik, N., \& Bandyopadhyay, S. (1992). Economic growth and environmental quality: Time series and cross-country evidence (English). Policy, Research Working Papers; No. WPS 904. World Development Report, World Bank Group.

Shahbaz, M., Hye, Q. M. A., Tiwari, A. K., \& Leitão, N. C. (2013). Economic growth, energy consumption, financial development, international trade and $\mathrm{CO} 2$ emissions in Indonesia. Renewable and Sustainable Energy Reviews, 25, 109-121.

Shahbaz, M., Nasreen, S., Ahmed, K., \& Hammoudeh, S. (2017). Trade openness-carbon emissions nexus: The importance of turning points of trade openness for country panels. Energy Econ, 61, 221-232.

Sinha, A., Shahbaz, M., \& Balsalobre, D. (2017). Exploring the relationship between energy usage segregation and environmental degradation in N-11 countries. J Clean Prod, 168, 1217-1229.

Tachie, A. K., Xingle, L., Dauda, L., Mensah, C. N., Appiah-Twum, F., \& Mensah, I. A. (2020). The influence of trade openness on environmental pollution in EU-18 countries. Environmental Science and Pollution Research, 1-21.

Tamazian, A., \& Rao, B. B. (2010). Do economic, financial and institutional developments matter for environmental degradation? Evidence from transitional economies. Energy economics, 32(1), 137-145.

Uzar, U., \& Eyuboglu, K. (2020). Do natural resources heal the environment? empirical evidence from Turkey. Air Quality, Atmosphere \& Health, 1-10.

Westerlund, J. (2007). Testing for Error Correction in Panel Data. Oxford Bulletin Of Economics and Statistics. 69(6), ss:709-748

World Bank, (2021). World Development Indicators. https://databank.worldbank.org/home.aspx

Zhang, S., Liu, X., \& Bae, J. (2017). Does trade openness affect CO2 emissions: evidence from ten newly industrialized countries?. Environmental Science and Pollution Research, 24(21), 17616-17625. 